\title{
Phytochemical and Ethnopharmacological Evaluations of Methanolic Extracts of Seed Coat of Manilkara Zapota: In-vitro \& In-vivo Approaches.
}

\author{
Joushan Ara*, Md. Abdul Kaium Siddiki, Arif Ahmed, Priyanka Paul and Md. Shahidul Islam \\ Department of Pharmacy, University of Science and Technology Chittagong (USTC), Bangladesh
}

*Corresponding author: Joushan Ara, Department of Pharmacy, University of Science and Technology Chittagong (USTC), Chattogram, Bangladesh.

To Cite This Article: Joushan Ara, Abdul Kaium Siddiki, Arif Ahmed, Priyanka Paul, Shahidul Islam, Phytochemical and Ethnopharmacological Evaluations of Methanolic Extracts of Seed Coat of Manilkara Zapota: In-vitro \& In-vivo Approaches. Am J Biomed Sci \& Res. 2021 - 12(1). AJBSR. MS.ID.001701. DOI: 10.34297/AJBSR.2021.12.001701.

Received: 眥 December 29, 2020; Published: 眥 February 16, 2021

\begin{abstract}
The plant Manilkara zapota, commonly known as chicle or sapodilla, is a slender, slow-growing, pyramidal evergreen tree that is native from southern Mexico to Costa Rica. This plant is spread all over the world including American tropics, Spain, Brazil and Bolivia, Pakistan, Srilanka etc. Phytochemical \& Ethnopharmacological Evaluations of Methanolic Extracts of Seed Coat of Manilkara Zapota: In-vitro and In-vivo approaches have been investigated. It was used in ancient system of medicine in many countries but not to great extent. The fruit is used as reducing infections, in viral disease, bacterial infections, in tooth cavity, blood cell formation. Moreover, it also used in swelling, as a pain relief agent. It is suggested for the insomnia and panic disorder. More over Sapodilla fruit is full of vitamin A, C and B complex. So, its beneficial for good health, eye and tooth. In the Phytochemical screening the methanolic extract of Manilkara zapota seed coat showed the presence of alkaloid, flavonoid, carbohydrate, glycoside, tannin.

The methanolic extract of Manilkara zapota seed coat showed 56.23\% potential activity of HRBC membrane stabilization (anti-inflammatory activity) compared to standard diclofenac. The methanolic extract of seed coat also produced $60.44 \%$ antioxidant activity compared to standard ascorbic acid. So, the methanolic extract of Manilkara zapota seed coat exhibited the moderate free radical scavenging activity (anti-oxidant activity). Methanolic extract of Manilkara zapota seed coat has a good analgesic and neuropharmacological activity. Therefore, Manilkara zapota seed coat has a guiding competence for the improvement of innovative superior efficacy drug in future.
\end{abstract}

\section{Introduction}

The numerous plants have therapeutic exploits and wield valuable the pharmacological upshots on the animal bodies are typically assigned as the "Medicinal Plants". At the same time as there is the no perceptible morphological asset in the medicinal plants producing with them, as far as this they have more than a few special qualities that generate them medicinally so significant [1]. Over last few decades, exercise of herbal drugs has been accentuated due to their effortless availability, therapeutic impending, slightest side effects in addition to minimum cost. At current nearly $80 \%$ of the world population relies on plant-based drugs for their health care need [2]. Presently, phytoconstituents are playing pivotal role for development of novel compounds, which might be crucial for maintaining a healthy society. [1] The human civilization has been maintaining an intimate relationship with the plants from time immemorial [3].

They depend on plants and other natural sources for their wellbeing and survival. Various plants still available in the nature are yet to be explored for their medicinal potential. Uses of computational chemistry to discover, enhance, or study drugs and related biologically active molecules. The most fundamental goal is to predict whether a given molecule will bind to a target and if so, how strongly [4]. Molecular mechanics or molecular dynamics are most 
often used to predict the conformation of the small molecule and to model conformational changes in the biological target that may occur when the small molecule binds to it [5]. This research work was carried out to evaluate the extract value, analgesic activity, antioxidant activity, anti-inflammatory and neuropharmacological activity of Manilkara zapota.

\section{Materials and methods}

The plant material named as Manilkara zapota based on its medicinal uses. Using standard taxonomical methods, the plants were collected from Chittagong division. It was then separated and cleaned from impurities (Figure A \& Table 1). The dried pure extracts were weighed separately with the help of electronic balance and the yield was determined by using the following formula [6].

\section{$\%$ of yield $=$ Weight of particular extract $/$ Total amount of coarse powder x 100}

\section{Quantitative analysis by DPPH Scavenging Antioxidant Activity [7]}

The antioxidant potentialof the methanolic extract was determined on the basis of their scavenging activity of the stable 1 , 1-diphenyl-2-picryl hydrazyl (DPPH) free radical. DPPH is a stable free radical containing an odd electron in its structure and usually utilized for detection of the radical scavenging activity in chemical analysis. The aliquot of the different concentrations of the extract was added to $3 \mathrm{ml}$ of a $0.004 \%$ EtOH solution of DPPH. Absorbance at517 $\mathrm{nm}$ was determined after 30 minutes, and IC50 (Inhibitory concentration $50 \%$ ) was determined. IC50 value denotes the concentration of sample required to scavenge $50 \%$ of the DPPH free radicals. The formula used for $\%$ inhibition ratio is

$$
\% \text { inhibition }=(\text { Control }- \text { Sample } / \text { Control }) \times 100
$$

\section{Analgesic Test}

\section{Preparation of Test Dose}

The extracts were suspended in the vehicle. Various strengths were prepared from a stock solution $40 \mathrm{mg} / \mathrm{ml}$. The solutions were prepared freshly, and were administered orally. The Acetic acid induced writhing test method is given below [8]: a) Twenty albino swiss mice divided into four groups containing Five mice each. Doses of $200 \& 400 \mathrm{mg} / \mathrm{kg}$ for EEPEL p.o. were given to Group III \& IV respectively.

b) The reference group (Group II) received Diclofenac Na (50 mg/ $\mathrm{kg})$

c) The control group received normal saline (10 mL/kg). p. o. 30 minutes after treatment was carried out, each of the mice was administered with acetic acid $(0.7 \% \mathrm{v} / \mathrm{v}$ in saline, $10 \mathrm{~mL} / \mathrm{kg}$, i.p.) to create pain sensation.

d) Five minutes after the administration of acetic acid, the numbers of writhes were counted over a period of $15 \mathrm{~min}$. The response of was compared with those of the control group.

e) \% inhibition of writhing in comparison to control group was taken as an index of analgesia and was calculated using the following formula:

$$
\text { Inhibition }(\%)=[(\mathrm{Wc}-\mathrm{Wt}) \times 100] / \mathrm{Wc}
$$

Where, $\mathrm{W}_{\mathrm{c}}=$ average number of writhing reflexes in the control group

$\mathrm{W}_{\mathrm{t}}=$ average number of writhing in the test groups.

\section{Results and Discussion}

\section{Antioxidant Activity}

(Figure 1) By analyzing the above data, it revealed that the plant extracts may have moderate antioxidant effect which is probably mediated by lnhibition of DPPH free radical, which is responsible for oxidation.

\section{Anti-Inflammatory Activity [9]}

(Figure 2) It was observed from the present study that methanolic extract of has anti-inflammatory activity and activity increases with increasing extract concentration. The Maximum inhibition was found at $2000 \mu \mathrm{g} / \mathrm{ml}$ extract concentration which showed $56.23 \%$ inhibition compared to standard. The activity increases with increasing extract concentration.

Table 1: Phytochemical screening of Manilkara zapota.

\begin{tabular}{|c|c|}
\hline Phyto Constituents & Ethanol Extract of Manilkara Zapota \\
\hline Alkaloid & + \\
\hline Glycoside & + \\
\hline Tannins & + \\
\hline Steroids & + \\
\hline Saponins & + \\
\hline Flavonoids & - \\
\hline Gum & + \\
\hline
\end{tabular}
$(+)$ : Present
$(-)$ : Absent 


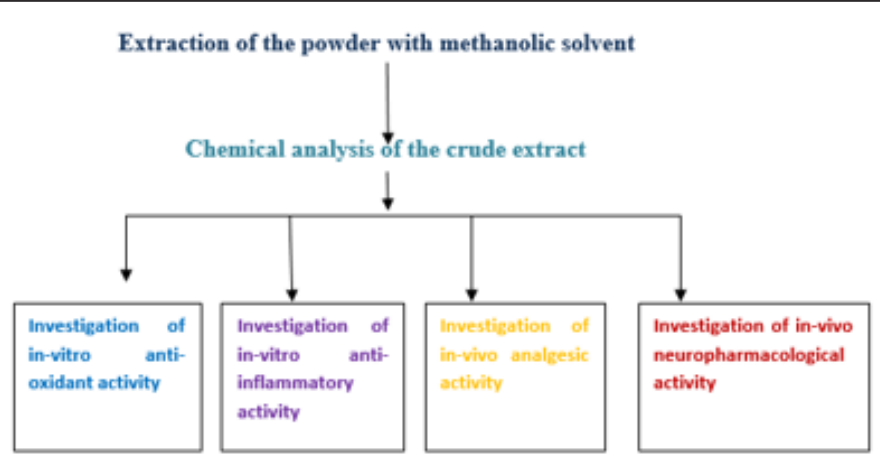

Figure A

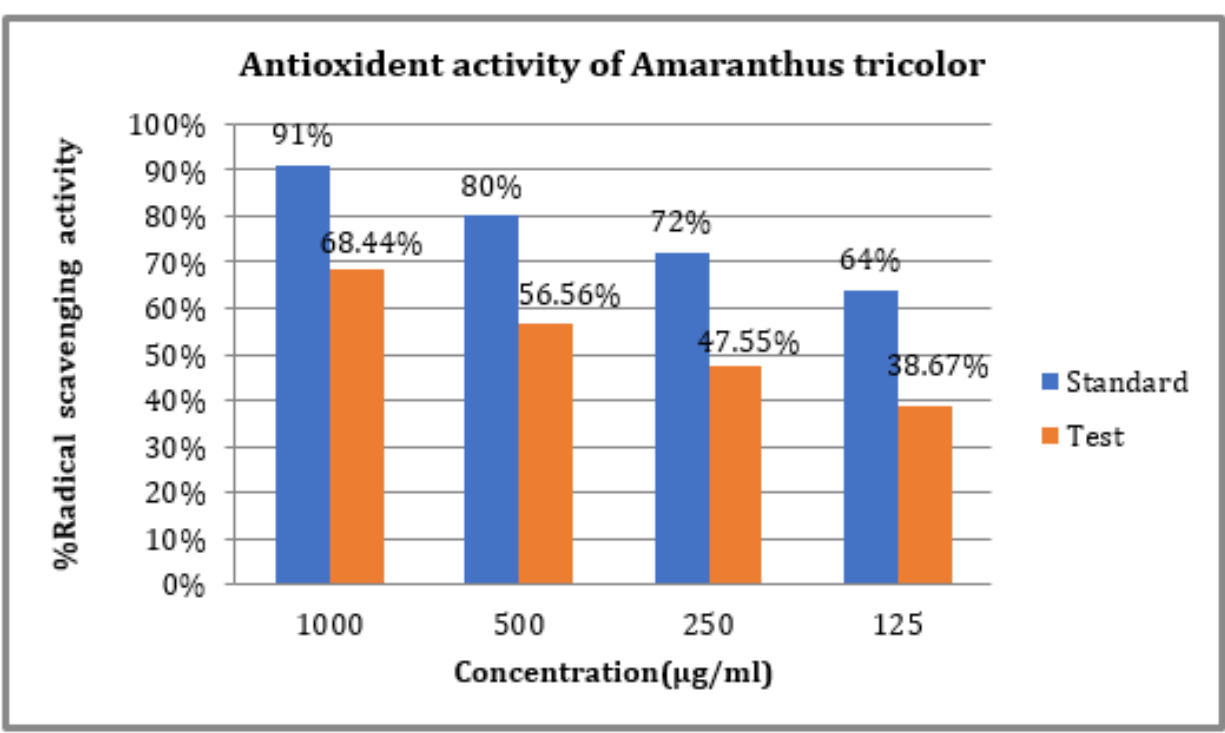

Figure 1: Antioxidant Activity of Manilkara zapota by DPPH SCV assay.

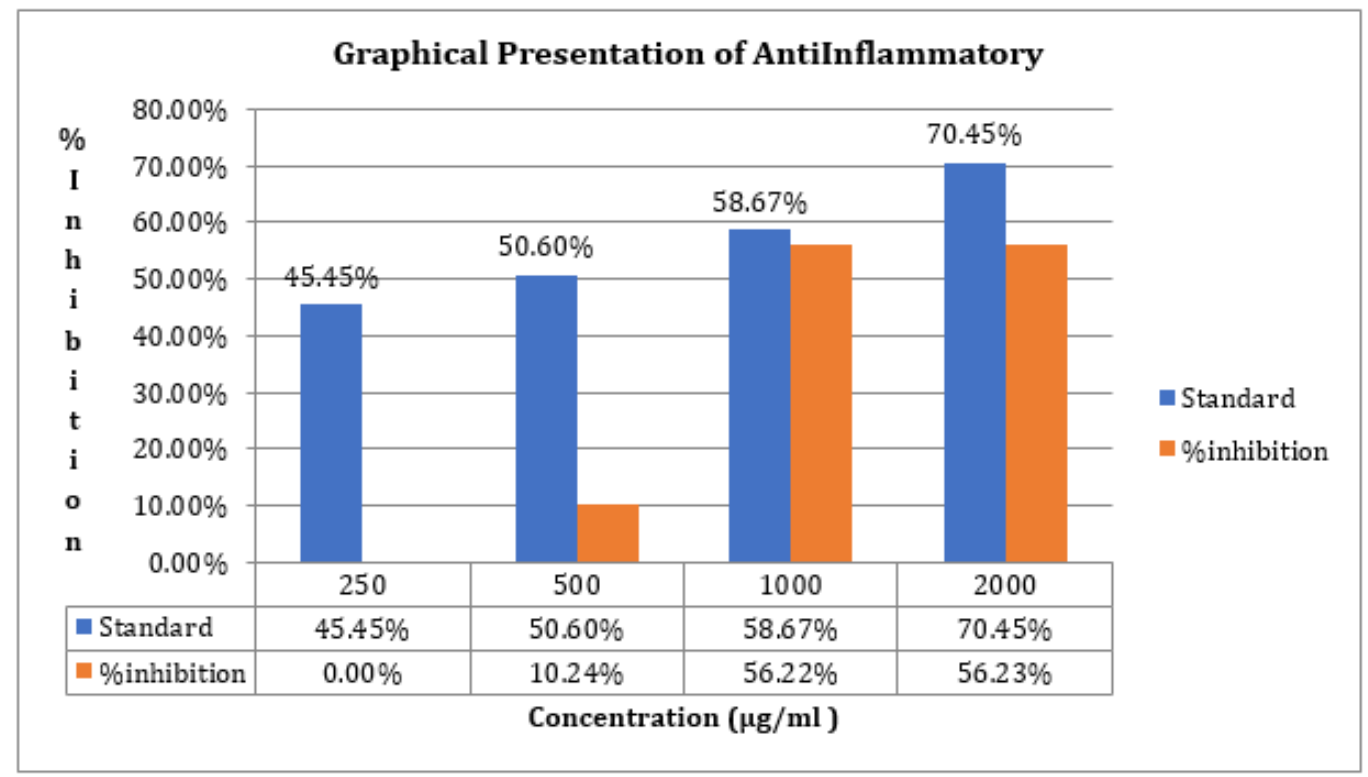

Figure 2: \% inhibition of Lagent of Manilkara zapota compared to standard. 


\section{Analgesic Analysis}

(Figure 3).

\section{Hot Plate Method for Analgesic Activity}

Groups of 12 mice (18-20g) are selected and divided into standard, test \& control group respectively. The temperature of the hot plate is maintained at $55^{\circ}$ to $56^{\circ} \mathrm{C}$. The animals are placed on the hot plate \& time until either licking or jumping occurs is recorded. The latency is recorded before \& after 20,60 and 90 min after the administration of standard or test compound (Figure 4). In acetic acid induced method, the metanolic extract of Malinkara zapota at the dose of 200 and $400 \mathrm{mg} / \mathrm{kg}$ body weight produced a gradual increase in the $\%$ inhibition compared to the control group. The standard drug diclofenac sodium produced $56.13 \%$ inhibition of writhing response at a dose of $50 \mathrm{mg} / \mathrm{kg}$. In hot plate method, the methanolic extract of Malinkara zapota at dose (200, $400 \mathrm{mg} / \mathrm{kg}$ ) body weight produced a high response. So, it is concluded that $\mathrm{Ma}$ linkara zapota have high analgesic activity.

\section{Neuropharmacological Activity [10]}

\section{Hole board method}

The methanolic extract of Manilkara zapota was subjected to screening for anxiolytic activity by hole board method. The test was performed by taking methanolic extract at doses of $200 \mathrm{mg} / \mathrm{kg}$ and $400 \mathrm{mg} / \mathrm{kg}$ body weight. The test results are annexed in table 1 and it represents the anxiolytic effect of methanolic extract of Manilkara zapota. The extract at the doses of $400 \mathrm{mg} / \mathrm{kg}$ have shown most moderate ameliorated the numbers of head dipping when compared to control and at the doses of $200 \mathrm{mg} / \mathrm{kg}$, the number of head dipping also increased moderately i.e., a dose dependent manner is observed in hole board method. Highly moderate increases were also observed in the number of head dipping in case of mice treated with diazepam $1 \mathrm{mg} / \mathrm{kg}$. So, the result was found statistically moderate (Figure 5).

\section{Open Field Method}

The methanolic extract of Manilkara zapota was subjected to screening for anxiolytic activity by open field method. The test was performed by taking methanolic extract at doses of $200 \mathrm{mg} / \mathrm{kg}$ and $400 \mathrm{mg} / \mathrm{kg}$ body weight. The methanolic extract of Manilkara zapota moderate decreased the number of squares passed by the animals i.e., the CNS depressant effect of MEMZ was proved by the behavior of mice in open field test (Figure 6).

\section{Rota Rod Method}

The methanolic extract of Manilkara zapota was subjected to screening for muscle coordination activity by Rota rod method. The test was performed by taking methanolic extract at doses of 200 $\mathrm{mg} / \mathrm{kg}$ and $400 \mathrm{mg} / \mathrm{kg}$ body weight. In this method mice falling from the rota rod in both diazepam $(1 \mathrm{mg} / \mathrm{kg})$ and MEAT-treated groups exhibited a moderate reduction in time spent by the mice in the rota rod test when compared with the control group i.e CNS depressant effects of the tested compound. The result was found statistically highly moderate (Figure 7).

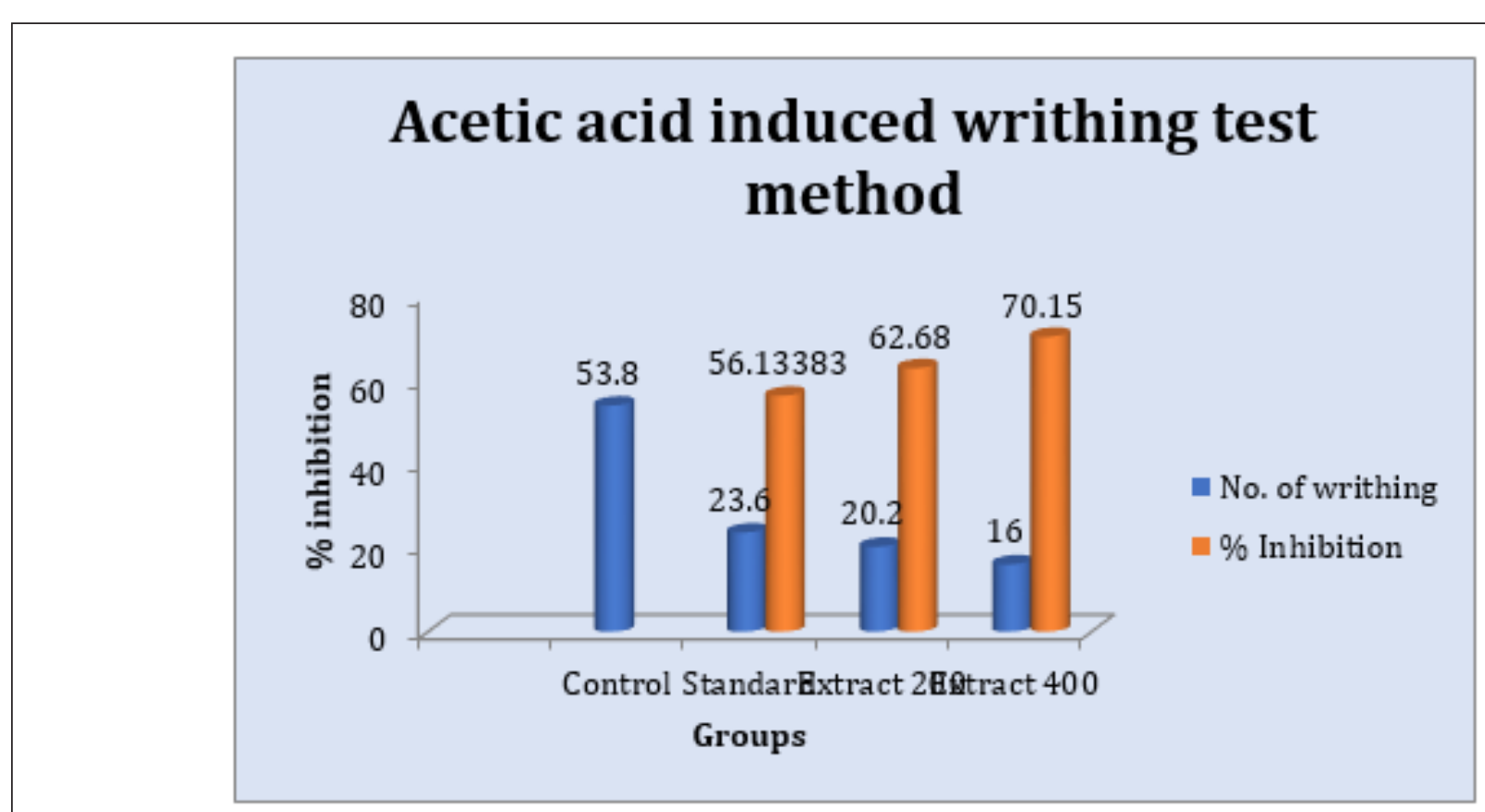

Figure 3: Graphical representation of data of Acetic acid induced writhing inhibition of Malinkara zapota Figure 3: Graphical representation of data of Acetic acid induced writhing inhibition of Malinkara zapota 


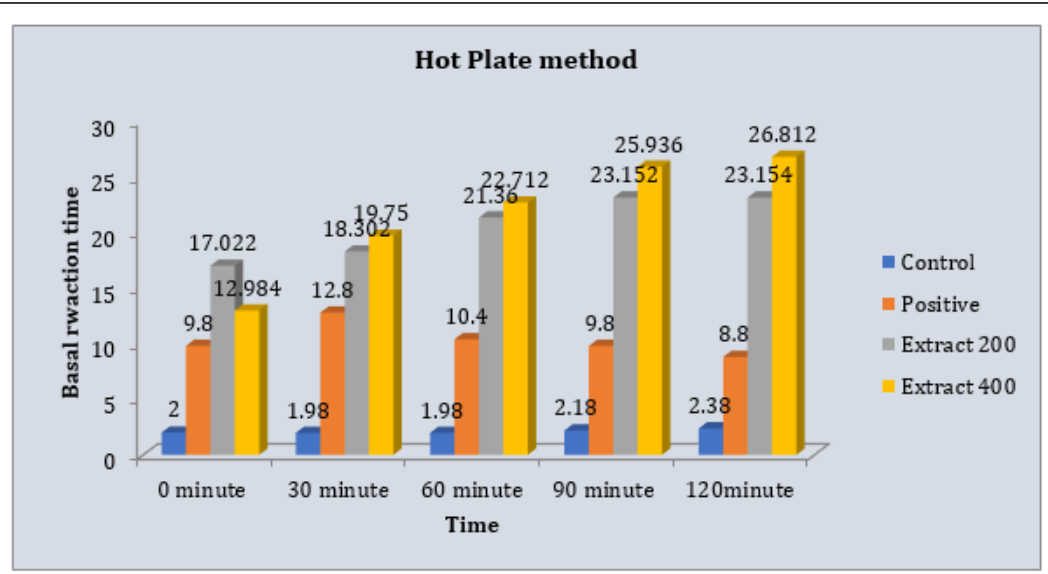

Figure 4: Graphical representation of data of Hot plate method test for Malinkara zapota.

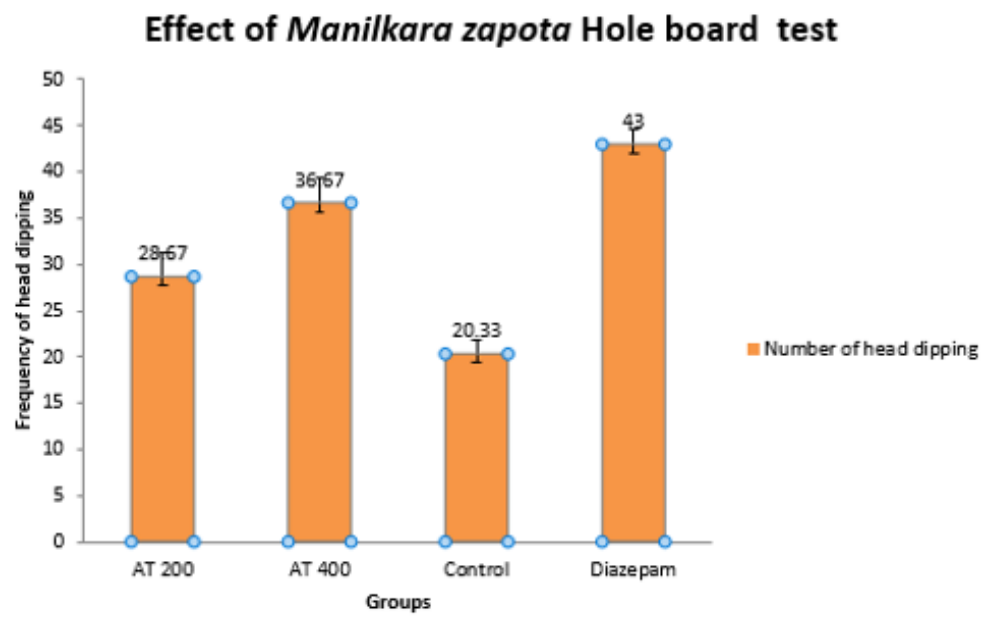

Figure 5: Graphical representation of MEMZ on mice in hole board test.

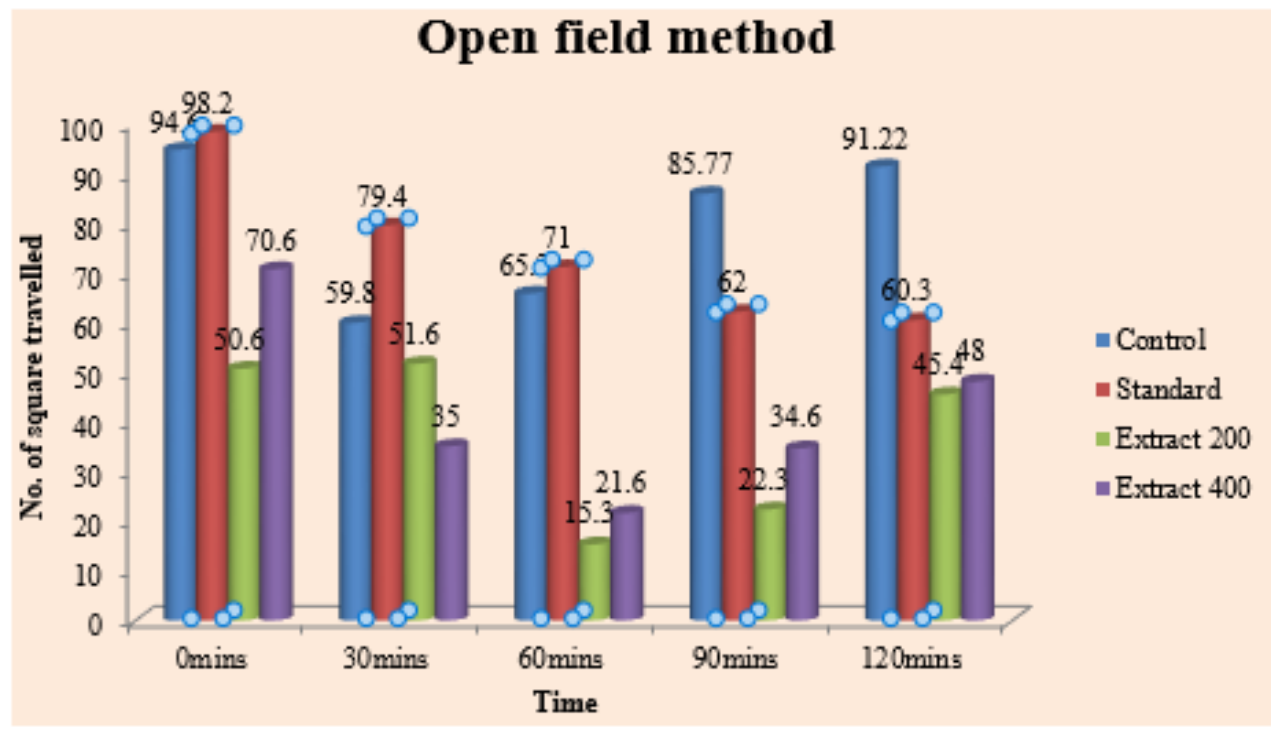

Figure 6: Effect of Manilkara zapota on mice in Open Field Method. 


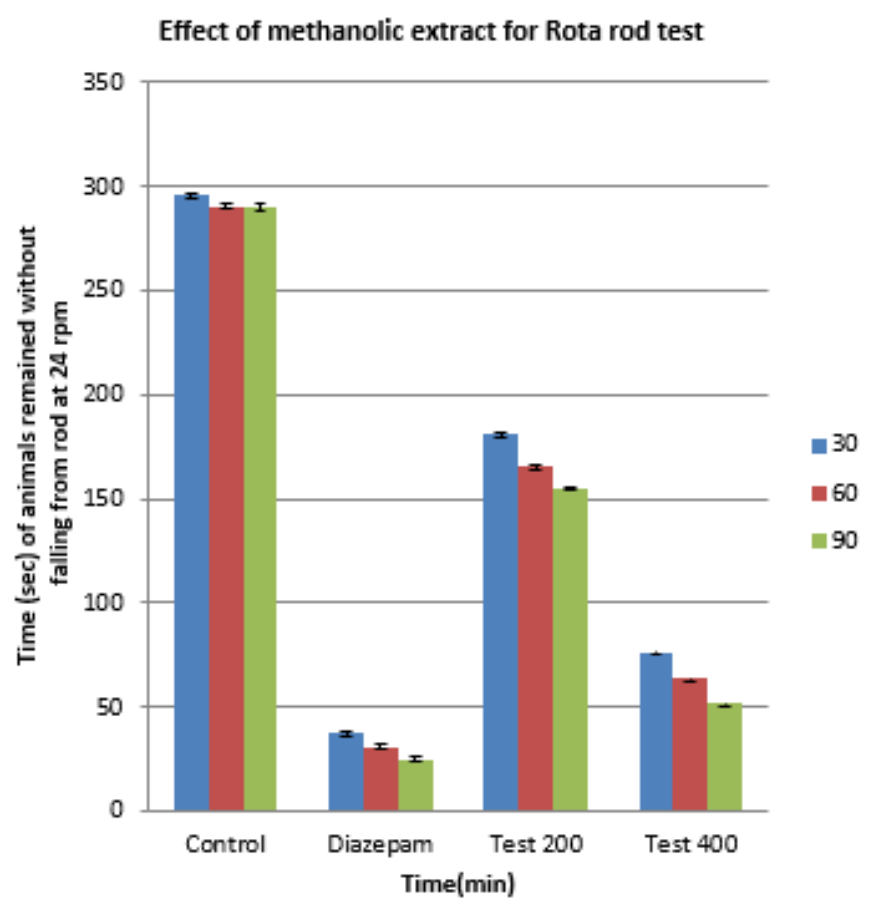

Figure 7: Effect of methanolic extract of Manilkara zapota on Rota rod test.

\section{EPM Method}

The methanolic extract of Manilkara zapota was subjected to screening for anxiolytic activity by EPM method. The test was performed by taking methanolic extract at doses of $200 \mathrm{mg} / \mathrm{kg}$ and 400 $\mathrm{mg} / \mathrm{kg}$ body weight. The methanolic extract of Manilkara zapota at the dose of $400 \mathrm{mg} / \mathrm{kg}$, moderate decreased the number of entries of mice into the open arms, and the time spent in the open arms of the EPM as shown in table 1. The effects of treatment of mice at the dose of $200 \mathrm{mg} / \mathrm{kg}$ on open arm entries and time spent in open arms were dose dependent. The standard drug (diazepam $1 \mathrm{mg} / \mathrm{kg}$, i.p) showed a significant increase in time spent in open arm and a significant increase in number of arm open arm entries. The result was found moderate anxiolytic (Figure 8).

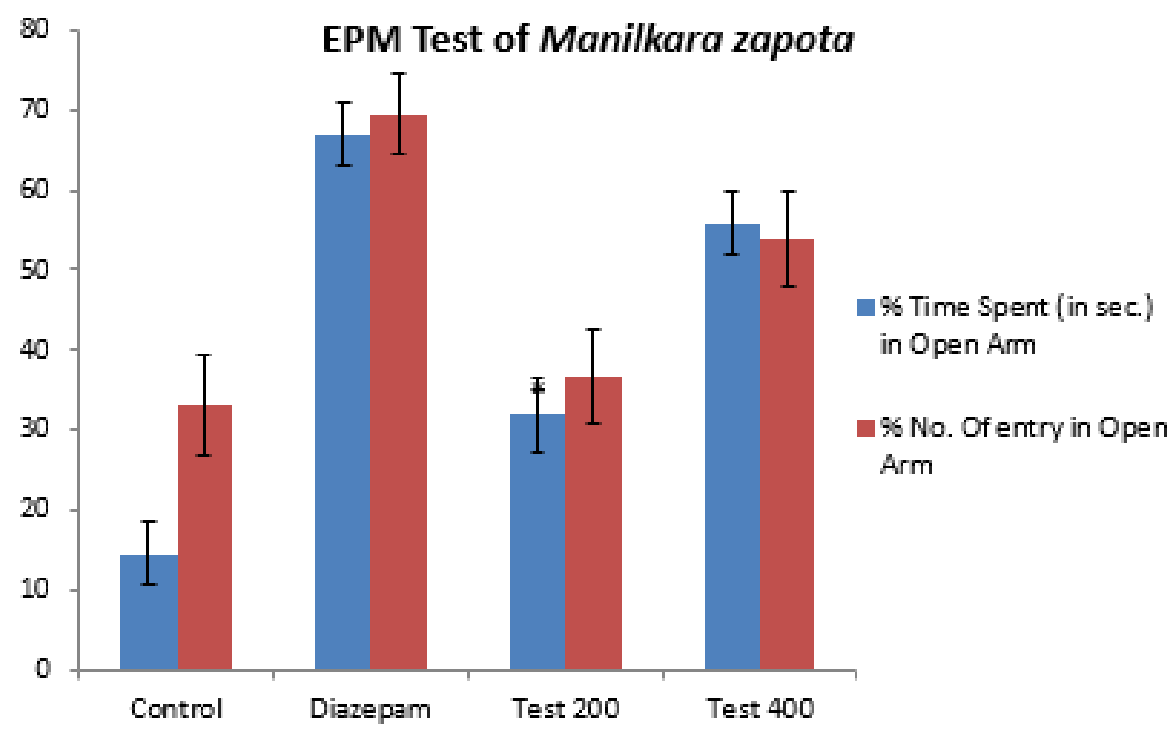

Figure 8: Effect of methanolic extract of Manilkara zapota on Rota rod test. 


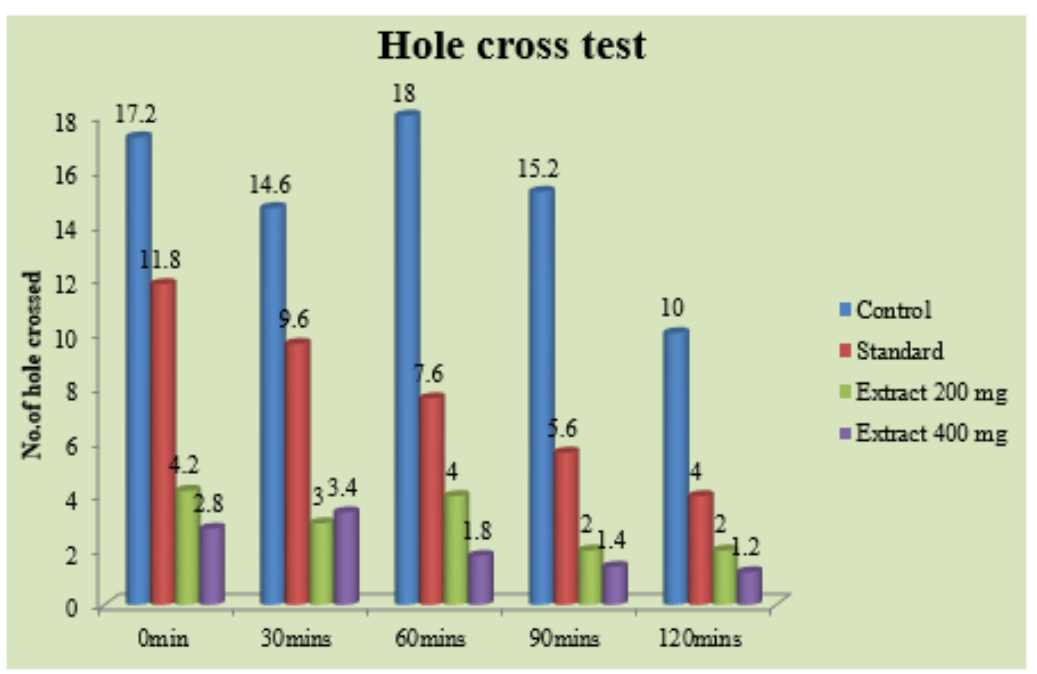

Figure 9: Graphical representation of Neuropharmacological effect of Manilkara zapota extract of Hole cross method.

\section{Hole Cross Method}

The methanolic extract of Manilkara zapota was subjected to screening for anti-depressant activity by hole cross method. The test was performed by taking methanolic extract at doses of 200 $\mathrm{mg} / \mathrm{kg}$ and $400 \mathrm{mg} / \mathrm{kg}$ body weight. The result was found moderate (Figure 9).

\section{Conclusion}

The results from the experiment confirmed that these may be potential candidate for the treatment of antioxidamt, anti-inflammatory, analgesic and neuropharmacological activity. Phytochemical study also reveals that the extracts contain several active groups such as alkaloids, glycosides, flavonoids, and tannins which may be responsible for the observed activities. So, this plant species could be useful in the search for new natural bioactive compounds. These findings show that the flower have potential therapeutic efficacy and may serve as potential source of chemically interesting and biologically important drug candidate and thus can be further screened against various diseases or using different in vitro and in vivo model in order to find out its unexplored efficacy.

This current study reported the neuropharmacology potential of methanolic extract of Manilkara zapota. After treatment of different doses of control, diazepam, methanolic extract of and comparing wit Manilkara zapota h control group it was established that MEMZ exerts a significant dose dependent neuropharmacological activity observed by hole board method, open field test, elevated plus-maze test, rota rod method and hole cross method. For CNS depressant effect, rota rod method, open field, hole cross test are used. Hole board, EPM test were done for angiogenic and anxiolytic activity. Hence Manilkara zapota has a leading capacity for the development of new good efficacy drugs in future.

\section{References}

1. Das JK, Kandar CC, Dey SP, Mandal S C (2011) Evaluation of Analgesic Activity of Clerodendrum Viscosum Linn. (Verbenaceae) Leaves on Experimental Animal Model. International Journal of Pharma \& Biosciences 2(2): 345-349.

2. Sermakkani M, Thangapandian V (2012) GC-MS analysis of Cassia Italica leaf methanol extract. Asian J Pharm Clin Res 5(2): 90-94.

3. Sanjib Shil, Manabendra Dutta Choudhury, Soumita Das (2014) Indigenous knowledge of medicinal plants used by the Reang tribe of Tripura state of India. J Ethnopharmacol 152(1): 135-141.

4. Zimmermann M (1983) Ethical guidelines for investigations of experimental pain in conscious animals. Pain 16(2): 109-110.

5. Barros HMT, Tannhauser MAL, Tannhauser SL, Tannhauser M (1991) Enhanced detection of hyperactivity after drug withdrawal with a simple modification of the open-field apparatus. J Pharmacol Methods 26(4): 269-275.

6. Hossein Hosseinzadeh, Shabnam Shahandeh, Shabnam Shahsavand (2012) Anxiolytic and Hypnotic Effects of Aqueous and Ethanolic Extracts of Aerial Parts of Echium italicum L. in Mice. Jundishapur J Nat Pharm Prod 7(2): 71-79.

7. Sudipta, Pallab K Haldar, Goutam Pramanik, Siva P Panda, Samit Bera, et al. (2010) Anticonvulsant activity of methanolic extract of Clerodendrum infortunatum Linn. in Swiss albino mice. Thai J Pharm Sci 34: 129-133.

8. Balemans MC, Huibers MM, Eikelenboom NW, Kuipers AJ, van Summeren RC, et al. (2010) Reduced exploration, increased anxiety, and altered social behavior: Autistic-like features of euchromatin histone methyltransferase 1 heterozygous knockout mice. Behav Brain Research 208(1): 47-55.

9. Prendergast BJ, Nelson RJ (2005) Affective responses to changes in day length in Siberian hamsters (Phodopus sungorus). Psychoneuroendocrinology 30(5): 438-452.

10.Daniels J (2009) Catatonia: clinical aspects and neurobiological correlates. The Journal of neuropsychiatry and clinical neurosciences. J Neuropsychiatry Clin NeuroscI 21(4): 371-380. 